\title{
To the Solution of Some Problems of Developing Assembly Technology by Modeling Assemblies in CAD Systems
}

\author{
Elena Samarkina \\ docent of the Department of Mechanical \\ Engineering \\ Pskov State University \\ Pskov, Russian Federation \\ ElenaSPsk@gmail.com \\ Evgenia Evgenjeva \\ vice head of the Department of Mechan- \\ ical Engineering \\ Pskov State University \\ Pskov, Russian Federation \\ zhen_sheny@mail.ru
}

\author{
Alexander Samarkin \\ docent of the Department of Medical \\ Informatics and Cybernetics \\ Pskov State University \\ Pskov, Russian Federation \\ alexsamarkinru@gmail.com
}

\author{
Sergey Dmitriyev \\ Head of the Department of Mechanical \\ Engineering \\ Pskov State University \\ Pskov, Russian Federation \\ dmitrievsi55@gmail.com
}

\begin{abstract}
Considers the features of the automated design of technological processes of assembly of products in mechanical engineering, in terms of their impact on production processes.
\end{abstract}

Keywords—assembly, computer-aided design, computer simulation, assembly tree.

\section{INTRODUCTION}

Experienced assembly technologists have always tried to adapt the available automation capabilities of design and graphic works to their needs. So, from the lists of drawings obtained in graphic editors with scissors, parts were cut out, laid out and glued in such a way as to obtain the required assembly unit (knot). In the process of unfolding, the composition of assembly units and the sequence of installation of parts and parts of the product in them were determined, which made it possible to analyse the variants of the assembly process and select the optimal one [6].

Currently, even for relatively simple parts, threedimensional modelling is used. In this case, the assembler technologist has to deal with three-dimensional models of parts and assemblies $[1,3]$. This led to the fact that some technologists are trying to "manipulate" three-dimensional models of assemblies (group models of product parts, taking into account the technological possibilities of manufacturing) in the CAD model space. The possibility of such a "manipulation" directly depends on the applied approach of design modeling of an assembly in a CAD environment, and these possibilities are not focused on assemblers.

In 1996, Intergraph launched the SolidEdge system, a tool designed to perform a set of work on solid-state modeling in the Windows environment on PC-class computers [2].

\section{ASSEMBLING FROM BOTTOM TO TOP}

SolidEdge has become one of the first successful implementations of approaches that allow working with assembly in the traditional, customary manner for a modern designer [4].

The SolidEdge system was originally designed for parametric solid-state modelling of subassemblies. Namely, for positioning parts of a product or creating new ones with reference to elements of a structure that already exist in the model assembly space. New parts can be created using neighbouring elements.

Subsequently, this idea of parametric solid-state modelling spread to almost all modern CAD designed for modelling assemblies. Let us analyse two main approaches of design solid-state modelling "bottom-up" and "top-down" for solving the problems of developing assembly technology [7].

Briefly, the bottom-up design modelling approach implemented in CAD comes down to the following steps:

- at the first stage details are modelled;

- on subsequent models of nodes are created from previously created models of parts;

- at the last stage, when all nodes are modelled, they are added to the product assembly.

Using the same CAD capabilities, an assembly technologist can "assemble" assembly units from readymade construction models of parts, thereby determining the sequence of their assembly and composition. The sequence of assembly will be determined by the order of inclusion of models of parts (nodes), and the composition of the models of parts (nodes) in the composition of the assembly model. 
In the technological model of the assembly, as in the design model, the creation history is graphically represented by an object - an acyclic, directed graph containing the history of model building (often called the construction tree, or, more briefly, the tree) of the assembly model. The tree is a single-level, ordered structure that reflects the order in which the models of parts (nodes) are included in the assembly model.

With respect to assembly modelling tasks, you can relate a timeline and an assembly tree. The starting point of time on the timeline will be related to the first part of the product that falls into the assembly, that is, the one that is highest in the assembly tree. Then all the parts that are lower in the tree fall into the assembly later in time than the first. One part of the product, located above the other part in the assembly tree, will join earlier than the other.

Thus, we can talk not only about the history of the assembly model, but also about the assembly process that develops over time, and about the modelling of the assembly process itself and at the same time using the same tools for creating assembly models as in the design.

The tree of the design model of the assembly is traditionally used as a means of navigation and editing. The tree of the technological model expands the indicated applications and allows, editing, to influence the technological sequence of assembly. It can be considered that in terms of content such a tree approaches a technological assembly scheme.

For this purpose, SolidEdge includes a navigator that displays the tree-like assembly structure and helps you navigate complex nodes, select and use the necessary parts for work, and also manage the assembly visualization process on the screen.

\section{AsSEMBLING FROM TOP TO BOTTOM}

Unlike the designer, the technologist, determining the order of entry into the assembly of models of parts of the product, sets not only the bindings (parametric and dimensional links), but also takes into account the technological capabilities of the assembly (access to the installation site, preserving integrity when moving, stability in the assembly process, etc.) [8,9].

Thus, using CAD it is possible to "manually", that is, without involving additional algorithms for making decisions about rearrangements and grouping the structure of the product model, to solve the following problems of designing an TP assembly:

- determine the composition of the assembly units (perform technological division);

- determine the sequence of installation of parts and assembly units in the assembly process.

- generate data for the list of product assembly (assembly units of different levels).

The nuance to which attention should be paid is that the assembly technologist re-executes the constructor's actions and must be proficient in the methods of working with CAD.

The longer the designer works at the same workplace, and the more he accumulates product models, the less often he will resort to bottom-up design. This is due to the fact that for real production rarely completely unique designs are created, changes are often local in nature. Therefore, it is more expedient to use the top-down approach for cases where there are one or more analogues.

The essence of the top-down design modelling approach implemented in CAD comes down to the following steps:

- at the first stage, borrowing models of assembly units and editing geometric and dimensional relationships;

- at subsequent stages, models of assembly units and parts are created with reference to already existing parts of the structure (in the context of assembly);

- at the last stage, when all nodes are modelled, they are added to the overall assembly of the product (if not the whole product was borrowed).

It would seem that an assembly technologist could use the "top down" approach, take design models of nodes as analogy models and break them down into technological ones at their own discretion. However, in modern CAD there is no tool that allows you to quickly break a large number of previously imposed assembly constraints without subsequently occurring errors and inconsistencies. The solution to this problem becomes the more complicated the more parts in the original assembly unit and, accordingly, the greater variety of geometric and dimensional constraints connecting the parts of the assembly at the point of rupture.

In this case, it may be a surrogate decision to extinguish (make non-visible) a part of the product that will not get into the assembly unit, which the technologist works with. A surrogate solution is also the use of a tab with performances, where each version will contain the state of the assembled product, starting from an assembly unit consisting only of parts, ending with a product. In this way, the technological composition can be fixed at the assembly stage, but the tree will not reflect the assembly sequence.

I would like to hope that the realization of the inconsistencies and difficulties in using three-dimensional models to perform tasks related to the development of assembly processes will force software developers to take a new look at the problem and as a result, a new tool or module will appear in the CAD that is addressed to to the collector.

\section{Conclusion}

In the precomputer era, engineers had to submit sequences of assembly / disassembly, maintenance, or repair using posters with so-called "spaced assemblies". Thanks to these posters it was possible to display intermediate results of the assembly in the sequence of its implementation.

The function of creating views with "separated" assembly components (the English term "exploded view" - Exploded View), is currently implemented in many CAD (Sol-id Works, Solid Edge, etc.) both in standard form and in the form of plug-in software. modules (SolidWorks Composer or CATIA Composer). 
According to the authors, the use of these tools is the most accessible and easy-to-use means of technological modelling of the assembly process today.

At present, methodological recommendations have been developed on the use of distributed species for technological modelling of the assembly process.

The essence of this approach is reduced to the following stages:

- at the first stage, borrowing models of assembly units of the design model of a product is performed;

- on the following - the models of assembly units and parts of all, except for those joined by the first (one or several assembly transitions), are hidden;

- using the Exploded View tool creates an "exploded assembly" of visible elements of the assembly. The results of the assembly are recorded in a graphic file that displays the states before and after the attachment or as a video;

- then the following elements attached to the already "assembled" parts become visible;

- their separation is also carried out by editing the exploded "exploded view", and the results are recorded;

- at the last stage, when all assembly units and parts are visible, the technologist has a sequence of technological states describing the assembly technology.

Thus, the technologist can break the design model into technological assembly models and fix the assembly sequence at his own discretion.

According to the authors, for the widespread use of this technique in production, only the capabilities of Exploded View are not enough. The assembly process is not only the joining of parts of the product, as reflected in the design specification, but also the assembly and disassembly of elements of assembly devices and temporary, but necessary for performing operations, elements (protective covers, covers, etc.).

In this regard, the authors propose the development of a special library of three-dimensional models of assembly devices for assembly-welding on a universal assembly table, which are included in the technological model along with the design elements. Thus, it is possible to obtain graphic files, containing a full replacement of assembly operational sketches.

Analysis shows that the proposed method does not replace, but complements the traditional assembly scheme. At the same time, this technique requires a wellorganized organization of the storage of graphic files of the technological model, which can be implemented with modern document management systems (PDM), as implemented by standard CAD tools. It is also advisable to store these files as nested (reference) documents of assembly operations designed with the help of CAD software, thus complementing traditional operational sketches.

The described techniques reflect, on the one hand, the practical experience of the authors developed in advising a number of enterprises in the city of Pskov (OJSC TESO, OJSC Pleskava, OJSC ADS) in the process of integrated implementation of CAD systems, as well as more than 20 years of teaching experience at the University of Pskov. Some results are reflected in articles [] and textbooks [9].

\section{REFERENCES}

[1] ISO 16792:2015(en). Technical product documentation — Digital product definition data practices. [Электронный ресурс]. URL: https://www.iso.org/obp/ui/\#iso:std:iso:16792:ed-2:v1:en (дата обращения: 20.11.2018).

[2] Scott Knoche. Embrace Model Based Definition. Quality magazine. July 1, 2006.

[3] Ma, Qin Yi; Song, Li Hua; Xie, Da Peng; Zhou, Mao Jun (2017). "Development of CAD Model Annotation System Based on Design Intent". Applied Mechanics and Materials. 863: 368-72. doi:10.4028/www.scientific.net/AMM.863.368.

[4] Uski, Pekka; Pulkkinen, Antti; Koskinen, Kari T. (2016). Aaltonen, Jussi; Virkkunen, Riikka; Koskinen, Kari T.; Kuivanen, Risto, eds. Can a sheet metal product be manufactured without drawings? Product lifecycle's point of view (PDF). Proceedings of the 1st Annual SMACC Research Seminar 2016. Tampere: Tampere University of Technology. pp. 109-11. ISBN 978-952-15-3832-2.

[5] Quintana, Virgilio; Rivest, Louis; Pellerin, Robert; Kheddouci, Fawzi (2012). "Re-engineering the Engineering Change Management process for a drawing-less environment". Computers in Industry. 63 (1): 79-90. doi:10.1016/j.compind.2011.10.003.

[6] Kovalchuk E.R., Kosov M.G., Mitrofanov V.G., et al. Fundamentals of automation of machine-building production: A textbook for universities / Ed. Yu. M. Solomentsev. - Moskow: Higher School, 1999. 312 p. (In Russian)

[7] Baranchukova I.M., Gusev A.A., Kramarenko Yu.B., et al. Designing Automated Engineering Technology: A Textbook for High Schools, Ed. Yu. M. Solomentsev. Moscow: Higher School, 1999. 416 p. (In Russian)

[8] Mrochek J.A., Zholobov A.A., Akulovich L.M. Fundamentals of automated production technology in mechanical engineering: Tutorial. Minsk: IPE Technoprint, 2003. 304 p. (In Russian)

[9] Timiryazev V.A., Skhirtladze A.G., Solnyshkin N.P., Dmitriev S.I., Evgenieva E.A. Designing technological processes of machine-building production: Textbook. Sankt-Petersburg: Lan publishing house, 2014. 384 p. (In Russian)

[10] Timiryazev V.A. et al. Production technology and computer-aided design of technological processes in engineering: a textbook. Stary Oskol: TNT, 2017. 319 p. ISBN 978-5-94178-557-5. (In Russian)

[11] Scientific basis for automating the assembly of machines. Ed. Novikov M.P. - Moscow: Mashinostroenie, 1976. 472 p. (In Russian)

[12] Samarkina E.I. Aggregate reconfiguration of an analog model of machine building images. Memoirs of the Pskov Polytechnic Institute. St. Petersburg, Pskov, St. Petersburg State Technical University Publishing House, 1998, No. 2, .- p. 92-96

[13] Samarkina E.I., Dmitriev S.I., Samarkin A.I., Evgenieva E.A. Analysis of the features of automated design of technological processes of assembly in mechanical engineering. Bulletin of the Pskov State University. Series "Technical Sciences". Issue 2.Pskov: Pskov State University, 2015. - p. 19-27 